\section{Salmonella enterica prevalence in finishing pigs at slaughter plants in Northern Italy}

\author{
Irene Alpigiani, Cristina Bacci, \\ Elisa Lanzoni, Franco Brindani, \\ Silvia Bonardi \\ Unità Operativa di Ispezione degli \\ Alimenti di Origine Animale, \\ Dipartimento di Scienze Medico \\ Veterinarie, Università di Parma, Italy
}

\section{Abstract}

Finishing pigs carrying Salmonella enterica are believed to be the main source of carcass contamination at the beginning of slaughtering. The aim of this study was to assess the $S$. enterica carrier status of finishing pigs at herd level by sampling pooled faeces on farm and mesenteric lymph nodes at slaughter in the North East of Italy. Environmental faecal samples belonging to 30 batches of pigs were collected on farm. At slaughter, mesenteric lymph nodes were collected from five randomly selected pigs per batch. S. enterica was isolated from 16 lymph nodes out of 150 (10.6\%) and from seven out of 30 (23.3\%) faecal samples. Four batches (13.3\%) were positive to $S$. enterica both in lymph nodes and in faeces. The number of batches positive to $S$. enterica either in lymph nodes or in faeces was 13 out of 30 (43.3\%). The most prevalent serovars from lymph nodes were $S$. Derby (25.0\%) and $S$. Typhimurium monophasic variant 1 , 4,[5],12:i:- (18.6\%), which were also isolated from faecal material (14.3 and $42.8 \%$ respectively). Contaminated faecal material or lymph nodes could be a primary source of carcass contamination at slaughter during evisceration. S. enterica contamination is widespread on pig farms and carrier pigs pass undetected the inspection visits at slaughter, entering the food chain. Therefore, in order to control $S$. enterica in pigs, the need to quantify possible risk factors at slaughter and develop effective management strategies on farm is of paramount importance to ensure food safety.

\section{Introduction}

Food business operators involved at any level of the food chain have to comply with community and national legislative provisions related to the control of hazards in primary production, including programmes for the monitoring and control of zoonoses and zoonotic agents (Regulation No 852/2004/EC and Directive 2003/99/EC; European Commission, 2003, 2004). One of the main concerns arising from food safety issues is that carrier animals infected by foodborne pathogens may pass undetected the meat inspection procedures, thus entailing risks of contamination for the meat production chain (European Food Safety Authority, 2011b).

Based on surveillance system, the main microbiological threats in developed countries were identified among bacterial zoonoses, such as thermotolerant Campylobacter, Salmonella, Yersinia enterocolitica and verocytotoxin producing Escherichia coli, mainly excreted via faeces from sub-clinical animals (European Food Safety Authority, 2011b). Thus, the potential carcass contamination at slaughter becomes not only a major public health but also an economic concern for the food industries (Rostagno, 2009).

In 2011, the number of reported human Salmonella cases continued to decrease, and 95,548 confirmed cases (notification rate 20.7 cases per 100,000 population) were reported by 27 European Member States (European Food Safety Authority, 2013). Nevertheless, salmonellosis is still the second most frequently reported zoonosis in Europe. In 2011, 3,344 cases of Salmonella were reported in Italy (European Food Safety Authority, 2013). Finishing pigs carrying Salmonella enterica are believed to be the main source of carcass and pork contamination at slaughter.

Meat inspection, both ante and postmortem, is a key factor of the overall surveillance system for pig health (European Food Safety Authority, 2011b). As part of the meat inspection process, the ante mortem inspection aims to prevent diseased animals entering in the food chain. Since sub-clinical animals often pass undetected through the ante and the post-mortem inspections, it is of paramount importance to enforce measures to control the Salmonella risk factors in pigs on farm and at slaughter plant in order to reduce the pathogen prevalence in the contaminated carcasses and viscera (Borch et al., 1996). In addition, surveillance programs aim to improve the understanding of the sources and the prevalence of Salmonella starting from the primary production. Although the eradication of the pathogen is rarely achievable, a reduction of the pathogen load by identifying which factors influence the animal carriage status could help in reducing the risk to human health in an integrated food chain plan (Milnes et al., 2009).

The aim of this study was to assess the $S$. enterica carrier status of finishing pigs at herd level and at slaughter by sampling pooled faeces on farm and mesenteric lymph nodes at slaughter in the North East of Italy.
Correspondence: Irene Alpigiani, Unià Operativa di Ispezione degli Alimenti di Origine Animale, Dipartimento di Scienze Medico Veterinarie, Università di Parma, Strada del Taglio 10, 43126 Parma, Italy.

Tel. +39.0251.032683 - Fax: +39.0521 .902742 .

E-mail: irene.alpigiani@nemo.unipr.it

Key words: Food safety, Finishing pigs, Salmonella enterica.

Conflict of interests: the authors declare no potential conflict of interests.

Received for publication: 24 April 2013. Revision received: 17 September 2013. Accepted for publication: 14 October 2013.

This work is licensed under a Creative Commons Attribution 3.0 License (by-nc 3.0).

(C) Copyright I. Alpigiani et al., 2014 Licensee PAGEPress, Italy

Italian Journal of Food Safety 2014; 3:1609 doi:10.4081/ijfs.2014.1609

\section{Materials and Methods}

\section{Study and design sample}

The entire study was carried out according to the routine commercial activity of each slaughter plant without interfering with their operations either on farm or at slaughter plant facility. Only finishing pigs from the slaughter plants were included in the study. Sampling was carried out from April to November 2012.

Three pig slaughter plants, named as I, II and III, were selected in the North East of Italy on the basis of their willingness to cooperate and taking into account the variability of the distribution of the types of farming systems. From slaughter plant I and III, five farms were selected and two batches of pigs per farm were included in the study. From slaughter plant II four farms were selected instead of five, because we tested four batches of pigs from one farm y (Table 1). A total of 14 different farms (named A-P) were included in the study and 30 batches of pigs were tested. All the farms supplying pigs to slaughter plants I and II and one farm supplying pigs to slaughter plant III were intensive farms, rearing pigs for the Parma ham protected designation of origin (PD0) production system. The semi free range farms produced extensive Nero di Parma pigs. Each batch of pigs was composed by animals living in several pens. The average size of the farms was 6351.7 (SD 5020.8) and ranged from 13 to 16,000 pigs. The total number of pens that were included in the study was 159 with an average number of pens per farm of 5.3 (range: 1-11 pens). 


\section{On-farm environmental faecal samples collection}

Environmental faecal samples belonging to the 30 batches of pigs were collected on farm the week before slaughtering. From each batch, one sample of faeces of at least $25 \mathrm{~g}$ was collected in each corresponding pen, according to the Commission Decision (EC) 55/2008 (European Commission, 2008). Thirty samples of faeces were collected in total. Faecal sampling was carried out by using sterile equipment. Sampling material was transported to the laboratory under controlled conditions and processed on the day of arrival.

\section{Samples collection of the mesenteric lymph nodes at slaughter plant}

On the day of slaughtering, the selected batch was sampled along the slaughter line. A minimum of $15 \mathrm{~g}$ of mesenteric lymph nodes (from at least five nodes) was collected from each of the five randomly selected pigs. Overall, 150 mesenteric lymph nodes samples were collected. Mesenteric lymph nodes were aseptically removed, placed in a sterile bag and transported to the laboratory under controlled conditions and processed on the day of arrival.

\section{Isolation of Salmonella enterica}

Mesenteric lymph nodes were first rinsed with sterile water. A $10 \mathrm{~g}$ - aliquot of mesenteric lymph nodes was processed according to the ISO 6579:2002 method (ISO; 2002a). A 10 galiquot of environmental faecal samples was analysed following the ISO 6579:2002/Amd 1:2007 method, Annex D (ISO, 2002b).

Xylose-Lysine-Desoxycholate (XLD) agar and Brilliant Green Agar were used as selective media showing typical Salmonella reactions were further tested with $\mathrm{API}{ }^{\circledR} 20 \mathrm{E}$ micro-substrate system (bioMérieux, Marci l'Etoile, France). Salmonella enterica serotyping was performed according to the White-KauffmannLe Minor scheme by slide agglutination with 0 and $\mathrm{H}$ antigen specific sera by the Istituto Zooprofilattico della Lombardia ed Emilia Romagna (Parma, Italy).

\section{Results}

Results are shown in Table 2. A total of 16 lymph nodes out of 150 (10.6\%) was positive for $S$. enterica. A total of 7 out of 30 (23.3\%) batches tested positive for $S$. enterica. Four batches (13.3\%) were positive to $S$. enterica, in lymph nodes and faeces. The number of batches positive to $S$. enterica either in lymph nodes or in faeces was 13 out of 30 (43.3\%). The serovars isolated from the lymph nodes were the follow-
Table 1. Study design.

\begin{tabular}{lccc} 
Slaughter plant & Farm & Batch & Type \\
I & A & 2 & Intensive \\
& B & 2 & Intensive \\
& C & 2 & Intensive \\
& D & 2 & Intensive \\
& E & 2 & Intensive \\
II & F & 2 & Intensive \\
& G & 2 & Intensive \\
& H & 2 & Intensive \\
& I & 4 & Intensive \\
\hline III & L & 2 & Semi-free range \\
& M & 2 & Organic \\
& N & 2 & Semi-free range \\
& O & 2 & Organic \\
& P & 2 & Intensive \\
Total & 14 & 30 & \\
\hline
\end{tabular}

Table 2. Prevalence of Salmonella enterica in faeces and lymph nodes in finishing pigs.

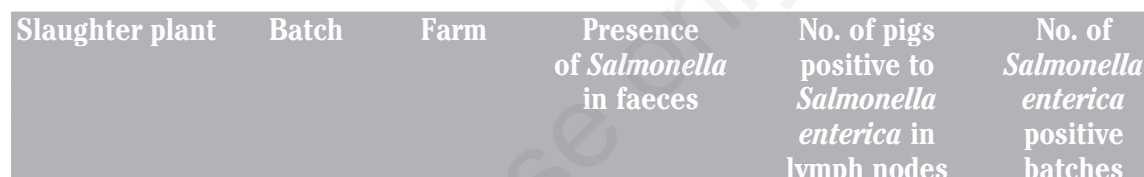

\begin{tabular}{|c|c|c|c|c|c|}
\hline I & 1 & A & - & 0 & 0 \\
\hline I & 2 & A & - & 1 & 1 \\
\hline I & 3 & B & + & 0 & 1 \\
\hline I & 4 & B & - & 0 & 0 \\
\hline I & 5 & $\mathrm{C}$ & - & 0 & 0 \\
\hline I & 6 & C & - & 0 & 0 \\
\hline I & 7 & $\mathrm{D}$ & - & 0 & 0 \\
\hline I & 8 & $\mathrm{E}$ & - & 0 & 0 \\
\hline I & 9 & $\mathrm{E}$ & - & 0 & 0 \\
\hline I & 10 & D & - & 0 & 0 \\
\hline II & 11 & $\mathrm{~F}$ & - & 3 & 1 \\
\hline II & 12 & $\mathrm{~F}$ & - & 0 & 0 \\
\hline II & 13 & $\mathrm{G}$ & - & 0 & 0 \\
\hline II & 14 & G & - & 0 & 0 \\
\hline II & 15 & $\mathrm{H}$ & - & 2 & 1 \\
\hline II & 16 & $\mathrm{H}$ & - & 0 & 0 \\
\hline II & 17 & I & - & 1 & 1 \\
\hline II & 18 & I & - & 0 & 0 \\
\hline II & 19 & $\mathrm{~F}$ & - & 1 & 1 \\
\hline II & 20 & $\mathrm{~F}$ & + & 0 & 1 \\
\hline III & 21 & $\mathrm{~L}$ & + & 0 & 1 \\
\hline III & 22 & $\mathrm{M}$ & + & 1 & 1 \\
\hline III & 23 & $\mathrm{~N}$ & - & 0 & 0 \\
\hline III & 24 & $\mathrm{~N}$ & - & 0 & 0 \\
\hline III & 25 & $\mathrm{M}$ & - & 1 & 1 \\
\hline III & 26 & $\mathrm{~L}$ & + & 3 & 1 \\
\hline III & 27 & 0 & + & 1 & 1 \\
\hline III & 28 & 0 & + & 2 & 1 \\
\hline III & 29 & $\mathrm{P}$ & - & 0 & 0 \\
\hline III & 30 & $\mathrm{P}$ & - & 0 & 0 \\
\hline Total & 30 & 14 & $7(23.3 \%)$ & $16(10.6 \%)$ & $13(43.3 \%)$ \\
\hline
\end{tabular}


ing: $4 S$. Derby, $2 S$. London, $2 S$. Give, $2 S$. Rissen, $2 S$. Typhimurium, $3 S$. Typhimurium monophasic variant $1,4,[5], 12:$ : : and $1 S$. Braenderup. The serovars isolated from the faecal samples were: $3 S$. Typhimurium monophasic variant 1, 4, [5],12:i:-, $2 S$. London, $1 S$. Derby and $1 S$. Give.

\section{Discussion and Conclusions}

In our study $23.3 \%$ of the environmental faecal samples and $10.6 \%$ of the mesenteric lymph nodes were Salmonella-positive. Many authors reported different values of prevalence from ileocaecal lymph nodes in different countries (Methner et al., 2011; Vico et al., 2011; Visscher et al., 2011). All Salmonella-positive finishing pigs tested in this study entered in the food chain. They were sub-clinical carriers of $S$. enterica, since they were subjected to the ante and post mortem inspection and no symptoms of salmonellosis were observed. It can be concluded that the ante and post mortem inspections is not accurate indicators of the $S$. enterica status on farm and at slaughter. Salmonella-positive faecal material or lymph nodes from these carrier animals could be a primary source of carcass contamination during evisceration at slaughter.

In line with Visscher et al. (2011), we consider that the types of sample used in our study are good epidemiologic indicator of the presence of Salmonella enterica both on farm (environmental faecal sampling representative of individuals living in a pen) and at slaughter plant (mesenteric lymph nodes representative of the entire batch). In fact environmental faecal samples are the most appropriate tool to assess the hygienic status of a herd since the ubiquitous $S$. enterica are resistant in pigs environment and can be representative of several individuals living in a pen (Belœil et al., 2004).

Berends et al. (1996), Borch et al. (1996) and Botteldoorn et al. (2003) estimated that ca 30\% of the pork carcass contamination is due to the carrier pig itself, and the remaining is caused by cross-contamination at the slaughter plant. It may be due to the hygienic procedures of the slaughter plant (Botteldoorn et al., 2003), which determine the presence on the resident slaughter plant bacteria (Gebreyes et al., 2004).

In our study the higher rate of positive match between environmental faecal samples and lymph nodes for $S$. enterica was observed in organic straw bedded and semi free range farms only. Similarly, Smith et al. (2011) found a higher prevalence of Salmonella in outdoor farming systems rather than indoor ones. Jensen et al. (2004) in fact were not able to demonstrate that organic rearing conditions were protective for pigs against $S$. enterica infections, as a high infection rate was found by the authors. In the same study the pathogen survived in the paddock environment for several weeks, and even an estimated low level of $S$. enterica was unable to protect newly introduced animals (Jensen et al., 2004). Therefore, the high rate of positive match between Salmonella-positive faecal samples and lymph nodes observed in our study could be explained by the close contact between pigs in the hut and by their rooting behaviour, which likely pose pigs at a high risk of ingestion of $S$. enterica from the contaminated environment. Magistrali et al. (2008) recognised the importance of the Salmonella contaminated environment as source of $S$. enterica infections in pigs. In fact $S$. enterica is able to survive in soil, water and on a variety of surfaces which gives the bacterium an increased likelihood of infecting new hosts; enhanced survival of Salmonella is favoured by a cyclic transmission from external environment to a new host (Winfield and Groissman, 2003).

$S$. Typhimurium and $S$. Derby are widespread and relevant in most European Member States, while other serovars, such as $S$. London, $S$. Infantis or $S$. Rissen are frequently isolated from pigs in some countries only, therefore their relevance cannot be generalised to the whole European Union (European Food Safety Authority, 2011a). In our study the most prevalent serovars were $S$. Derby in mesenteric lymph nodes and $S$. Typhimurium monophasic variant 1, 4,[5],12:i:- in the faecal material, confirming previous data (European Food Safety Authority, 2011a). In line with our results, Wilkins et al. (2010) observed an association between $S$. Derby and the growing-finishing pigs in Canada. Similarly, Belœil et al. (2004) reported a higher prevalence of $S$. Derby (51.4\%) and $S$. Typhimurium (37.8\%) in finishing pigs in France; De Busser et al. (2011) identified as the predominant serotypes $S$. Typhimurium (58.7\%) and $S$. Derby (17.4\%) in pigs in Belgium; according to Visscher et al. (2011) S. Typhimurium (87.0\%), was the predominant serovar in Germany. $S$. Typhimurium monophasic variant 1, 4,[5],12:i:-, which was detected both in animal and environment-related samples, has already been reported by many EU countries (European Food Safety Authority, 2010). In Spain, Vico et al. (2011) detected emerging monophasic variant $S$. enterica 1, 4,[5],12:i:multi antibiotic-resistant isolates. Therefore, this emerging serotype requires a strict and continuous surveillance update in Europe.

S. enterica contamination is widespread on pig farms and carrier pigs usually pass undetected the inspection at slaughter, entering in the food chain. Therefore, in order to control $S$. enterica in pigs, we need to quantify possible risk factors at slaughter and to develop effective management strategies on farm to ensure food safety. Risk factors on farm include allin/all-out systems, rodent control, no access of pets and birds, visitor hygiene and no close contact with other production animals. Moreover, farmers should avoid the introduction of subclinically infected pigs and implement the above mentioned Salmonella- control procedures. Nevertheless, hygiene standards of pork carcasses at slaughter continue to be essential to control the risk of Salmonella contamination.

\section{References}

Belœil PA, Fravalo P, Fablet C, Jolly JP, Eveno E, Hascoet Y, Chauvin C, Salvat G, Madec F, 2004. Risk factors for Salmonella enterica subsp. Enterica shedding by market-age pigs in French farrow-to-finish herds. Prev Vet Med 63:103-20.

Berends BR, Urlings HAP, Snijders JMA, Van Knapen F, 1996. Identification and quantification of risk factors animal management and transport regarding in Salmonella spp. in pigs. Int J Food Microbiol 30:37-53.

Borch E, Nesbakken T, Christensen H, 1996. Hazard identification in swine slaughter with respect to foodborne bacteria. Int $\mathrm{J}$ Food Microbiol 30:9-25.

Botteldoorn N, Heyndrickx M, Rijpens N, Grijspeerdt K, Herman L, 2003. Salmonella on pig carcasses: positive pigs and cross contamination in the slaughterhouse. $\mathrm{J}$ Appl Microbiol 95:891-903.

De Busser EV, Maes D, Houf K, Dewulf J, Imberechts $\mathrm{H}$, Bertrand S, De Zutter L, 2011. Detection and characterization of Salmonella in lairage, on pig carcasses and intestines in five slaughterhouses. Int J Food Microbiol 145:279-86.

European Commission, 2003. Directive of the European Parliament and of the Council on the monitoring of zoonoses and zoonotic agents, 2003/99/EC. In: Official Journal, L $325 / 31,12 / 12 / 2003$.

European Commission, 2004. Regulation of the European Parliament and of the Council on the hygiene of foodstuffs, 852/2004/EC. In: Official Journal, L 139/1, $30 / 4 / 2004$.

European Commission, 2008. Commission Decision concerning a financial contribution from the Community towards a survey on the prevalence of Salmonella spp. and Methicillin-resistant Staphylococcus aureus in herds of breeding pigs to be carried out in the Member States, Annex 1 Part B, 55/2008/ EC. In: Official Journal, L 14/10, 17/1/2008.

European Food Safety Authority, 2010. Scientific opinion on monitoring and assessment of the public health risk of "Salmonella Typhimurium-like" strains. 
EFSA J 8:1826.

European Food Safety Authority, 2011a. Analysis of the baseline survey on the prevalence of Salmonella in holdings with breeding pigs, in the EU, 2008. Part B: factors associated with Salmonella pen positivity. EFSA J 9:2329.

European Food Safety Authority, 2011b. EFSA panels on biological hazards (BIOHAZ), on contaminants in the food chain (CONTAM) and animal health and welfare (AHAW). Scientific opinion on the public health hazards to be covered by inspection of meat (swine). EFSA J 7:2351.

European Food Safety Authority, 2013. The European union summary report on trends and sources of zoonoses, zoonotic agents and food-borne outbreaks in 2011. EFSA J 11:3129.

Gebreyes WA, Davies PR, Turkson P-K, Morrow WEM, Funk JA, Altier C, 2004. Salmonella enterica serovars from pigs on farms and after slaughter and validity of using bacteriologic data to define herd Salmonella status. J Food Protect 67:691-7.

ISO, 2002a. Microbiology of food and animal feeding stuffs. Horizontal method for the detection of Salmonella spp. ISO Norm 6579:2002. International Standardization Organization ed., Geneva, Switzerland.

ISO, 2002b. Annex D: detection of Salmonella spp. in animal faeces and in environmental samples from the primary production stage. ISO Norm 6579:2002/Amd 1:2007. International Standardization Organization ed., Geneva, Switzerland.

Jensen AN, Lodal J, Baggesen DL, 2004. High diversity of Salmonella serotypes found in an experiment with outdoor pigs. NJASWagen J Life Sc 52:109-17.

Magistrali C, Dionisi AM, De Curtis P, Cucco L, Vischi 0, Scuota S, Zicavo A, Pezzotti G, 2008. Contamination of Salmonella spp. in a pig finishing herd, from the arrival of the animals to the slaughterhouse. Res Vet Sci 85:204-7.

Methner U, Rammler N, Fehlhaber K, Rösler U, 2011. Salmonella status of pigs at slaughter: bacteriological and serological analysis. Int J Food Microbiol 151:15-20.

Milnes AS, Sayers AR, Stewart I, Clifton-Hadley FA, Davies RH, Newell DG, Cook AJC, Evans SJ, Smith RP, Paiba GA, 2009. Factors related to the carriage of Verocytotoxigenic E. coli, Salmonella, thermophilic Campylobacter and Yersinia enterocolitica in cattle, sheep and pigs at slaughter. Epidemiol Infect 137:1135-48.

Rostagno MH, 2009. Can stress in farm animals increase food safety risk? Foodborne Pathog Dis 6:767-76.

Smith RP, Sanchez-Vazquez MJ, Cook AJC,
Edwards SA, 2011. Abattoir-based study investigating the association between gross pathological lesions and serological tests for Salmonella infection in pigs. Vet Rec 168:240.

Vico, JP, Rol I, Garrido V, San Román B, Grilló MJ, Mainar-Jaime RC, 2011. Salmonellosis in finishing pigs in Spain: prevalence, antimicrobial agent susceptibilities, and risk factor analysis. J Food Protect 74:1070-8.

Visscher CF, Klein G, Verspohl J, Beyerbach M, Stratmann-Selke J, Kamphues J, 2011. Serodiversity and serological as well as cultural distribution of Salmonella on farms and in abattoirs in Lower Saxony, Germany. Int J Food Microbiol 146:44-51.

Wilkins W, Raji c A, Waldner C, McFall M, Chow E, Muckle A, Rosengren L, 2010. Distribution of Salmonella serovars in breeding, nursery, and grow-to-finish pigs, and risk factors for shedding in ten farrowto-finish swine farms in Alberta and Saskatchewan. Can J Vet Res 74:81-90.

Winfield MD, Groisman EA, 2003. Role of nonhost environments in the lifestyles of Salmonella and Escherichia coli. Appl Environ Microb 3687-94. 